\title{
Medios digitales de calidad en los procesos de conocimiento y didáctica del patrimonio cultural
}

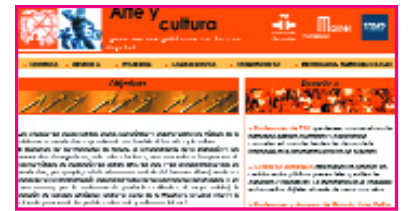

Página principal de la web del curso Arte y Cultura
La difusión de los contenidos culturales afronta en la actualidad una multiplicidad de nuevos canales (Internet, productos interactivos offline, televisión por banda ancha, canales temáticos, soportes móviles) que, aparte de su posible convergencia en un futuro no lejano, suponen otras tantas oportunidades para que nuevos públicos accedan al conocimiento del arte y la cultura. Con tal premisa, el curso Arte y cultura para nuevos públicos en la era digital -organizado por la Universidad Internacional Menéndez Pelayo (Valencia, 12 al 16 de julio de 2004)-, se centró en combinar las aportaciones de tecnólogos, gestores culturales, profesores universitarios, productores y distribuidores de contenidos, sociólogos y abogados, para abordar de forma interdisciplinar las implicaciones de este cambio cultural.

Manuel Castells y Manuel Campo Vidal, en el diálogo que abrió el seminario, expusieron claramente los procesos de deslocalización en curso, mediante los cuales determinados referentes culturales pasan a ser iconos transnacionales o sin identidad geográfica clara, quedando expuestos a nuevas miradas. Dichos procesos ofrecen tantos riesgos como oportunidades, pudiendo suponer pérdidas de identidad nacional o lingüística para algunos referentes culturales del mundo hispano, pero también la incorporación de otros más allá de las barreras del idioma. Por otra parte, se da igualmente una creciente independencia frente a los modelos existentes de industria cultural, con nuevos medios de distribución e intercambio de contenidos, que reclaman urgentemente una adaptación de los modelos de negocio a esas nuevas posibilidades.

Los directores del curso, Luis Cueto y Chimo Soler, del Instituto Cervantes, presentaron un ambicioso estudio sobre la posición de la cultura española en Internet. Mediante métodos cuantitativos y cualitativos, se fueron aproximando al peso relativo de la cultura española e hispanoamericana en la Red, y de lo que se pudo extraer que, en el ámbito de las artes plásticas, casi la mitad de los iconos culturales con más presencia en Internet son hispanos, pero que su importancia no viene dada por contenidos en español, sino fundamentalmente en inglés. En este punto se abre un campo de trabajo muy prometedor, para mantener esos y otros referentes culturales pero vinculándolos más al sector cultural y educativo hispanohablante.

Además de Internet, los nuevos canales de distribución audiovisual recibieron gran atención por parte de ponentes y público. Tecnologías como la emisión por banda ancha o la televisión digital terrestre ya hacen posible la distribución de contenidos audiovisuales mediante fórmulas radicalmente distintas a las conocidas: emisiones personalizadas, bajo demanda, por perfiles institucionales, sociales o educativos, etc. Para proporcionar contenidos a estos nuevos cauces van a ser necesarios nuevos perfiles profesionales, aunando tecnología y humanidades, que aún no reciben respuestas adecuadas por parte del sector educativo.

Sin embargo, la generación de contenidos culturales sin rigor o sin calidad didáctica supondría un serio retraso para la difusión de las TICs (Tecnologías de la Información y la Comunicación) entre el sector cultural y educativo, y por supuesto entre el público general. En ese sentido, Eduardo García Matilla señaló la urgencia de generar una masa crítica de usuarios, un público de productos culturales que garantice la viabilidad económica de esos nuevos canales audiovisuales.

Por su parte, expertos en gestión cultural como Juan Manuel Bonet o Felipe Garín explicaron su experiencia en la creación de valor añadido desde las instituciones culturales, principalmente los museos. Públicos presenciales y medios digitales, a juicio de los profesionales en difusión y didáctica de museos, no son términos contrapuestos, sino elementos que se complementan mutuamente. Como forma de concretar todo esta cuestión mediante ejemplos reales, grupos más reducidos pudieron utilizar diversas tecnologías en los talleres de tarde, con un enfoque más práctico. Mediante ejercicios presenciales y varias videoconferencias pudo permitirse el diálogo directo con profesionales relevantes en la aplicación de las TICs al patrimonio cultural, y la evaluación crítica de diversas iniciativas en marcha.

Este curso es fruto de la colaboración entre el Instituto Cervantes y el Departamento de Historia del Arte de la Universidad de Valencia, con el apoyo de la Fundación Mainel.

En el sitio web del curso -www.cervantes.es/uimp 2004- se puede acceder a una versión actualizada de sus contenidos, con parte de las ponencias presentadas, así como con otros materiales complementarios que sirvan de plataforma para la preparación de próximos encuentros presenciales y virtuales.

Luis Cueto y Álvarez de Sotomayor

Chimo Soler Herreros

Jorge Sebastián Lozano

Coordinadores del curso 